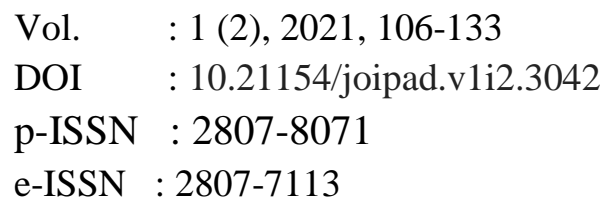

\title{
PERAN DAN STRATEGI LAZNAS NURUL HAYAT KANTOR CABANG MADIUN DALAM MENGENTASKAN MASALAH PEREKONOMIAN
}

\section{Novita Hanivatul Ummah ${ }^{1 *}$, Fauzan Adhima ${ }^{2}$, dan Rangga Ilham Pangestu Aji ${ }^{3}$, Ajeng Wahyuni ${ }^{4}$}

IAIN Ponorogo, Indonesia, info@iainponorogo.ac.id Institut Agama Islam Negeri Ponorogo, Indonesia Email: novitahanifa03@gmail.com,ranggailham359@gmail.com, fauzanngad@gmail.com, ajeng@iainponorogo.ac.id

\begin{abstract}
This study aims to examine the role and strategy of The Branch of LAZNAS Nurul Hayat based in Madiun that alleviating economic problems. In Islam, apart from being zakat, donations and alms are also effective solutions to poverty alleviation. Therefore we need zakat, infaq and alms management body that has a good management mechanism. It also has an optimal role in efforts to improve the economy of the community. The LAZNAS Nurul Hayat in Madiun formed in order to maximize zakat management and maximize the increase of the economy sector for the people in the Madiun area. The results of this study indicate that the existing zakat management mechanism of LAZNAS Nurul Hayat Madiun Branch is good enough. The role of zakat, infaq and alms is an effort to improve the economy for people in the Madiun area that form of consumptive assistance and productive assistance. Its implementation is based on Islamic law and law.
\end{abstract}

Keywords: Role, Strategy, Economic Problem, ZIS 
Abstrak: Penelitian ini bertujuan untuk mengkaji peran dan strategi LAZNAS Nurul Hayat Cabang Madiun dalam mengentaskan masalah perekonomian. Dalam Islam selain sebagai ibadah zakat, infak dan sedekah juga merupakan solusi efektif untuk penanggulangan kemiskinan. Oleh karena itu diperlukan sebuah badan pengelolaan zakat, infak dan sedekah yang memiliki mekanisme pengelolaan yang baik serta memiliki peran yang optimal dalam upaya peningkatan perekonomian pada masyarakat. LAZNAS Nurul Hayat Cabang Madiun dibentuk agar bisa memaksimalkan pengelolaan zakat dan memaksimalkan peningkatan perekonomian masyarakat di wilayah Madiun. Hasil penelitian ini menunjukkan bahwa mekanisme pengelolaan zakat yang ada LAZNAS Nurul Hayat Cabang Madiun sudah cukup baik. Adapun peranan zakat, infak dan sedekah dalam upaya meningkatkan perekonomian masyarakat di wilayah Madiun berjalan dalam bentuk bantuan konsumtif dan bantuan produktif. Pelaksanaannya dilakukan berdasarkan syariat Islam dan Undangundang.

Kata Kunci: Peran, Strategi, Masalah Perekonomian, ZIS

\section{PENDAHULUAN}

Islam sangat memegang tinggi prinsip solidaritas yang hakiki, telah banyak ajaran islam yang menganjurkan dan mewajibkan pemeluknya untuk memegang prinsip mulia yang disyari'atkannya. Islam merupakan agama yang bisa memberikan rahmat kepada manusia di dunia dan di akhirat. (Departemen Agama Republik Indonesia Jakarta: 2004, 461) Dalam ajaran islam, kita diwajibkan untuk menyisihkan sebagian harta yang dimiliki. Di antaranya adalah mengeluarkan zakat, infak, dan sedekah (ZIS). Dari ketiga amalan tersebut, zakat memiliki hukum wajib untuk dilaksanakan. Sementara infak dan sedekah hukumnya sunah.

Ketika melihat orang yang membutuhkan, umat islam diwajibkan untuk bersedekah dan meringanan beban mereka. Hal ini 
didasarkan tenggang rasa ke sesama umat dan juga kemanusiaan. ZIS sebagai salah satu cara menanggulangi kemiskinan yaitu dengan adanya dukungan dari orang yang mampu menggeluarkan hartanya untuk diberikan kepada yang membutuhkan. Jika dilihat dari pertumbuhannya, zakat mengalami perkembangan yang pesat, khususnya pada satu dakade terakhir. Akan tetapi pertumbuhan zakat tersebut masih sangat jauh dari potensi zakat sebenarnya. (BAZNAS: 2007, 2) Selama ini zakat masih dipandang sebelah mata bagi sebagian orang padahal ZIS memiliki peranan yang sangat besar dalam upaya peningkatan perekonomian dan penurunan tingkat kemiskinan di Indonesia. Selain itu, ZIS sebagai sebuah instrumen perekonomian islam dapat menjadi jembatan antara yang kaya dan yang miskin untuk mengatasi masalah kemiskinan.

Permasalahan ekonomi adalah hal yang krusial bagi kehidupan baik secara individu, masyarakat dan negara. Kesejahteraan dan ketenteraman hidup suatu negara dapat dilihat dari gambaran ekonomi masyarakatnya. (Muhammad: 2009, 58) Perekonomian saat ini menunjukkan bahwa masih banyak masyarakat yang belum terpenuhi hak atas kebutuhannya secara layak karena belum mendapat pelayanan sosial dari pemerintah. Negarapun harus ikut turun tangan untuk menyelesaikannya. Dengan demikian, untuk meningkatkan keadilan dan kesejahteraan masyarakat sehingga perlu diatur untuk meningkatkan daya guna dan hasil guna, zakat harus dikelola secara melembaga sesuai dengan syariat islam. UU 23 tahun 2011 tentang pengelolaan zakat untuk mengganti Undang-Undang Nomor 38 Tahun 1999 tentang pengelolaan zakat yang sudah tidak sesuai dengan 
perkembangan kebutuhan hukum dalam masyarakat sehingga perlu diganti dengan yang baru dan sesuai.

Kesadaran masyarakat untuk membayar zakat kini cenderung menngkat, namun potensi yang besar itu belum tergali secara optimal. Hal ini berkaitan dengan kepercayaan masyarakat kepada lembaga amil zakat yang masih kurang. Selain itu pendayagunaan zakat masih kurang karena masih bersiat konsumtif daripada produktif. Oleh karena itu, pengelolaan zakat di Indonesia harus menuju ke arah yang lebih baik. Pendistribusian zakat merupakan salah satu faktor yang dijadikan tolak ukur bagi umat islam untuk memilih lembaga yang dipercaya dalam pengelolaan zakat. Keberhasilan dari pengelolaan zakat sangat bergantung pada pendistribusian zakat tersebut. (Mardiantari: 2019, 151-165)

Yayasan Nurul Hayat atau Lembaga Amil Zakat Nasional (LAZNAS) Nurul Hayat Cabang Madiun bergerak dalam bidang layanan sosial dan dakwah dengan berfokus pada empat sektor yaitu sosial kemanusiaan, kesehatan, pendidikan, serta dakwah dan ekonomi. Nurul Hayat Cabang Madiun sebagai lembaga pengelolaan dan pendistribusian zakat, infak dan sedekah sudah banyak berkontribusi dalam upaya membangun dan mensejahterakan masyarakat, melalui berbagai macam program yang dikeluarkannya. Melalui Program-programnya, LAZNAS Nurul Hayat Cabang Madiun telah membantu mengentaskan masalah perekonomian di Indonesia terutama masalah perekonomian yang terjadi di wilayah Madiun, dan sekitarnya. Adapun program-program tersebut diantaranya yaitu, Insentif dan Pembinaan Potensi Guru Qur'an (IBUQU), Sumber Air 
Bersih, Layanan Ambulance, Santunan Bagi Penghafal Al-Qur'an (TAFAQUR), Bunda Yatim, dan sebagainya. (Majalah Nurul Hayat Madiun: 2020, 36)

LAZNAS Nurul Hayat Cabang Madiun memperoleh dana ZIS dari para donatur atau muzakki, baik donatur tetap maupun tidak tetap. Strategi fundrising yang dilakukan adalah melalui offline dan juga online. Karena masa pandemi sebagian donatur atau muzakki yang berzakat, infak, dan sedekah dengan transfer ke rekening resmi Nurul Hayat Cabang Madiun. Sebagian tetap dijemput dananya ke tempat masing-masing oleh tim fundraiser. Untuk biaya operasional dan gaji karyawan LAZNAS Nurul Hayat Cabang Madiun tidak mengambil dari dana zakat, infak, dan sedekah melainkan memenuhinya dari unit usaha, sehingga seratus persen dana umat tersalurkan untuk mendukung layanan sosial dan dakwah. Unit usaha LAZNAS Nurul Hayat Madiun di antaranya yaitu, program Aqiqah Siap Saji, BarBeKu (Barang Bekas Berkualitas), Herbal Shop, serta Travel Haji dan Umroh.

Banyak orang yang menilai bahwa pengelolaan zakat di LAZNAS Nurul Hayat Cabang Madiun berjalan dengan lancar dan sesuai dengan prosedur yang berlaku. Hal ini terbukti dengan diraihnya prestasi LAZNAS Nurul Hayat Cabang Madiun pada kejuaraan nasional saat konvensi tahun 2020 ini. Nurul Hayat Cabang Madiun telah mengukir prestasi pada dua kategori yaitu: 1) Pertumbuhan ZIS Terbaik Nasional dan, 2) Kepatuhan Kepada System Terbaik Nasional. Meskipun dalam kondisi pandemi Covid19, tentu tidak menyurutkan semangat LAZNAS Nurul Hayat Cabang Madiun untuk tetap kreatif dan berprestasi dalam berkontribusi. 
Penelitian ini akan mengungkapkan bagaimana peran dan strategi LAZNAS Nurul Hayat Cabang Madiun dalam upaya mengentaskan masalah perekonomian di Indonesia?

\section{KAJIAN TEORI}

\subsection{Sejarah Pengelolaan Zakat di Indonesia}

Regulasi zakat pertama di Indonesia adalah Surat Edaran Kementerian Agama No.A/VII/17367 tahun 1951 yang melanjutkan ketentuan ordonansi Belanda bahwa negara tidak mencampuri urusan pemungutan dan pemungutan zakat, tetapi hanya melakukan pengawasan. Menteri Agama mengirimkan RUU ke DPR-GR dengan Surat Nomor MA/095/1967. Menteri Agama menerbitkan Peraturan Menteri Agama No. 4 tahun 1968 tentang Pembentukan Badan Amil Zakat dan Peraturan Menteri Agama No 5 tahun 1968 tentang Pembentukan Baitul Mal yang berfungsi sebagai pengumpul zakat untuk kemudian disetor kepada BAZ Namun, atas seruan dan dorongan Presiden berturut-turut pada peringatan Isra' Mi'raj dan Idul Fitri 1968 keluarlah Instruksi Menteri Agama No.1 tahun 1969 tentang Penundaan PMA NO. 4 dan 5 tahun 1968.

Melalui perjuangan para ulama, cendekiawan dan profesional, pada tahun 1990-an mulai terlihat perubahan sikap politik pemerintah terhadap zakat. Di satu sisi, usaha untuk merintis pendirian lembaga zakat formal terus berlangsung. sehingga akhirnya berdiri lembaga zakat formal pertama, yaitu BAZIZ DKI pada tahun 1969. Kemudian pada tahun 1991, pemerintah mengeluarkan Surat Keputusan Bersama Menteri Dalam Negeri dan Menteri Agama Republik Indonesia 
Nomor 29 dan 47 Tahun 1991 tentang Pembinaan Badan Amil Zakat, Infaq dan shadaqah. Dan diikuti dengan Instruksi Menteri Agama Nomor 5 Tahun 1991 tentang Pembinaan Teknis Badan Amil Zakat, Infaq dan Shadaqah dan Instruksi Menteri Dalam Negeri Nomor 7 Tahun 1998 tentang Pembinaan Umum Badan Amil Zakat, Infaq dan Shadaqah.

Puncaknya adalah ketika pada tahun 1999, pemerintah bersama DPR menyetujui lahirnya Undang-Undang Nomor 38 Tahun 1999 tentang Pengelolaan Zakat. UU Pengelolaan Zakat Ini kemudian ditindaklanjuti dengan Keputusan Menteri Agam (KMA) Nomor 581 tahun 1999 tentang Pelaksanaan UU No3 tahun 1999 dan Keputusan Dirjen Bimas Islam dan Urusan Haji Nomor D/291 tahun 2000 tentang Pedoman Teknis Pengelolaan Zakat. Sebelumnya pada tahun 1997 juga keluar Keputusan Menteri Sosial Nomor 19 Tahun 1998, yang memberi wewenang kepada masyarakat yang menyelenggarakan pelayanan kesejahteraan sosial bagi fakir miskin untuk melakukan pengumpulan dana maupun menerima dan menyalurkan ZIS.

Setelah disahkannya UU No. 38 tahun 1999 tentang Pengelolaan Zakat Indonesia telah memasuki tahap institusionalisasi pengelolaan zakat dalam wilayah formal kenegaraan, meskipun masih sangat terbatas. Lembaga-lembaga pengelola zakat mulai berkembang. Termasuk pendirian lembaga zakat yang dikelola oleh pemerintah, yaitu BAZNAS (Badan Amil Zakat Nasional) dan lembaga zakat yang dikelola masyarakat dengan manajemen yang lebih baik dan modern.

\subsection{Pendayagunaan Zakat}


Di dalam undang-undang No. 38 tahun 1999 tentang pengelolaan zakat, Bab I, Ketentuan Umum pasal 1, disebutkan bahwa pengelolaan zakat adalah kegiatan perencanaan, pelaksanaan, dan pengawasan terhadap pengumpulan dan pendistribusian serta pendayagunaan zakat. Didalam pengelolaan zakat tentu ada pendistribusian zakat, empaat kategori pendistribusian zakat yaitu:

a. Konsumtif Tradisional

Pemberian dana zakat kepada mustahiq secara langsung untuk memenuhi kebutuhan sehari-hari. Pola yang digunakan semacam ini pola jangka pendek didalam mengentaskan masalah ekonomi umat

b. Konsumtif Kreatif

Pemberian dana zakat kepada mustahiq berupa pemberian barang konsumtif dan digunakan untuk memenuhi kebutuhan sosial dan ekonomi. Bentuk bantuan yang di berikan berupa alat-alat kebutuhan sekolah, bantuan alat-alat pertanian dan lain sebagainya

c. Produktif Konvensional

Zakat diberikan dalam bentuk barang-barang produktif, dimana dengan menggunakan barang-barang tersebut diharapkan mustahiq dapat memiliki dan menciptakan usaha sendiri untuk meningkatkan ekonomi, seperti pemberian bibit tanaman, alat pertukangan, hewan ternak, dan lain sebagainya.

d. Produktif Kreatif

Zakat yang diwujudkan dalam bentuk pemberian modal bergilir, baik untuk kegiatan sosial berupa permodalan maupun 
modal usaha untuk membantu atau untuk pengembangan usaha para pedagang kecil.

\subsection{Peran Zakat dalam Mengentaskan Kemiskinan}

Semua orang mendambakan hidup berkecukupan. Ada Pangan, pakaian, dan ada tempat tinggal. Inilah keperluan pokok minimum manusia yang harus dipenuhi. Kemudian biaya pendidikan dan kesehatan anak (keluarga), termasuk menjadi beban pemikiran orang tua. Namun, sebagian orang belum dapat mencapai dambaannya (keinginannya) itu. Maka dari itu fungsi zakat untuk membantu mengentaskan permasalahan perekonomian.

Zakat, baik pemungutan maupun penggunaannya bertujuan merealisasikan fungsi-fungsi sosial, ekonomi dan permodalan dalam masyarakat Islam, selain tujuan ibadah. Karena yang diharapkan oleh orang yang melakukan dan menunaikan zakat adalah pahala dari sisi Allah, baik di dunia maupun akhirat.

\section{METODE PENELITIAN}

\subsection{Jenis Penelitian}

Jenis Penelitian yang peneliti gunakan adalah jenis penelitian kualitatif. Penelitian ini dilakukan dengan terjun langsung ke lapangan (field research) sehingga bisa juga dikatakan sebagai penelitian sosiologis. Sedangkan menurut Soetandyo Wingjosoebroto sebagaimana yang dikutip oleh Bambang Sunggono dalam bukunya mengatakan bahwa penelitian sosiologis adalah penelitian berupa studi empiris yaitu penelitian untuk menemukan teori-teori mengenai proses terjadinya dan proses bekerjanya hukum dalam masyarakat. 


\subsection{Pendekatan Penelitian}

Pendekatan yang digunakan dalam penelitian ini adalah pendekatan yuridis-normatif, serta kualitatif deskriptif karena datadata yang dibutuhkan dan digunakan berupa selebaran selebaran informasi yang tidak perlu dikuantifikasi.

\subsection{Sumber Data}

a. Data Primer

Yaitu data yang diperoleh langsung dari sumber pertama dan utama yaitu pengurus dan amil LAZNAS Nurul Hayat Cabang Madiun dan UU RI No. 23 Tahun 2011 tentang pengeolaan zakat.

b. Data Sekunder

Yaitu data yang dikumpulkan diperoleh dari orang kedua atau pihak lain. Dalam hal ini, pelaksanaannya dengan cara meneliti bahan-bahan sekunder seperti literatur yang menunjang, hasil penelitian, skripsi, tesis, disertasi, makalah, majalah, bulletin, surat kabar dan internet.

\subsection{Waktu dan Lokasi Penelitian}

Penelitian ini dilaksanakan dalam kurun waktu satu bulan, yaitu dari tanggal 26 Oktober sampai 21 November 2020. Peneliti mengambil penelitian di Yayasan atau LAZNAS Nurul Hayat Cabang Madiun yang beralamatkan di Jl. Kapten Tendean No. 28 A, Sogaten, Sidorejo, Wungu, Madiun.

\subsection{Metode Pengumpulan Data}

Untuk menggali data peneliti menggunakan metode pengumpulan data sebagai berikut: 
a. Observasi

Yaitu dengan mengamati penglihatan dan pendengaran manusia yang diperlukan untuk menangkap gejala yang diamati. Dari hasil catatan tersebut selanjutnya dianalisis. Observasi bertujuan untuk menjawab masalah dalam penelitian ini dengan kinerja para birokrasi di LAZNAS Nurul Hayat Cabang Madiun.

b. Wawancara

Wawancara digunakan untuk mendapatkan data atau informasi mengenai mekanisme pengelolaan zakat di LAZNAS Nurul Hayat Cabang Madiun. Teknik wawancara yang digunakan peneliti adalah teknik wawancara yang tidak terstruktur, artinya pedoman wawancara hanya dibuat dengan garis besar yang akan dipertanyakan.

c. Dokumentasi

Adalah mencari data yang berupa catatan, majalah, dan sebagainya. Hal ini dilakukan untuk mendapatkan data-data yang berkaitan dengan pokok penelitian seperti data pelaksanaan program kerja lembaga, laporan keuangan, pengelolaan, perkembangan LAZNAS Nurul Hayat Cabang Madiun.

\subsection{Metode Pengolahan Data}

a. Editing (Pemeriksaan Data)

Peneliti meakukan proses editing terhadap hasil wawancara terhadap narasumber serta beberapa rujukan yang peneliti gunakan dalam menyusun penelitian ini.

b. Classifying (Klasifikasi)

Merupakan usaha untuk mempermudah menganalisis mengklasifikasi berbagai kategori. Semua data-data dipilah 
dalam bagian-bagian yang memiliki persamaan berdasarkan data yang diperoleh pada saat wawancara dan data yang diperoleh melalui referensi.

c. Verifying (Verifikasi)

Hal ini dilakukan untuk menjamin bahwa data yang didapat adalah benar-benar valid dan tidak ada manipulasi.

d. Concluding (Kesimpulan)

Kesimpulan inilah yang nantinya akan menjadi sebuah data terkait dengan objek penelitian peneliti.

\subsection{Metode Analisis Data}

Yaitu menganalisa masalah dari data-data yang telah dikumpulkan yang berkenaan dengan permasalahan yang dibahas, lalu disusun dan selanjutnya dianalisa, agar pembahasan tersebut sesuai dengan judul dan rumusan masalah. Dalam penelitian ini, metode analisis data yang digunakan peneliti adalah metode diskriptif yaitu penelitian yang bertujuan untuk mengemukakan data yang digambarkan dengan kalimat yang dipisah-pisahkan menurut kategori untuk memperoleh kesimpulan.

\section{PEMBAHASAN}

\subsection{Sejarah Berdirinya Yayasan Nurul Hayat}

Awal mula didirikannya Yayasan Nurul Hayat, berawal dari perkumpulan Bani Hayat di mana H. Muhammad Molik yang merupakan pendiri sekaligus ketua Yayasan Nurul Hayat ingin mengalokasikan 5\% dari hasil penjualan jamu maduranya (CV. Firda Prima) untuk diberikan kepada anak yatim. Setelah menyisihkan 
sebagian hasil dari penjualan untuk dishodaqohkan. Pada tahun 2001 Molik membuat panti asuhan yang diberi nama panti asuhan Nurul Hayat, dan pada akhirnya pada tahun 2004 panti asuhan Nurul Hayat dibubarkan dan berganti nama menjadi Yayasan Nurul Hayat. Dengan berganti nama dan menjadi sebuah yayasan sosial, maka Yayasan Nurul Hayat mulai mengembangkan ke berbagai kegiatan sosial lainnya.

Yayasan Nurul Hayat bergerak dalam bidang layanan sosial dan dakwah. Sejak awal didirikan, Nurul Hayat sudah dicita-citakan untuk menjadi lembaga milik umat yang mandiri. Lembaga milik umat artinya lembaga yang dipercaya oleh umat karena mengedepankan transparansi dan akuntabilitas pengelolaan dana-dana amanah umat. Sedangkan, lembaga yang mandiri artinya semua biaya operasional (termasuk gaji karyawan) berusaha dipenuhi secara mandiri dari hasil usaha yayasan. Oleh karena itu donasi dari umat berupa zakat, infak dan shodaqoh (ZIS) baik perorangan maupun lembaga, $100 \%$ tersalurkan untuk membiayai program layanan sosial dan dakwah Nurul Hayat.

Yayasan Nurul Hayat yang awalnya dikelola oleh keluarga, sekarang menjadi yayasan milik umat yang dikelola secara profesional, sehingga dibentuklah 3 direktorat yaitu: direktorat dana, direktorat program, dan direktorat usaha. Dimana 3 direktorat tersebut saling melengkapi dalam melaksanakan berbagai program Nurul Hayat. (Hasil wawancara: Direktur LAZNAS NH Madiun, 2020)

\subsection{Peranan LAZNAS Nurul Hayat Cabang Madiun}

Saat ini yang menjadi trend dari islamization process yang di kembangkan oleh para pemikir kontenporeer ekonomi islam adalah, 
pertama: mengganti ekonomi sistem bunga dengan sistem ekonomi bagi hasil (free interest), kedua: mengoptimalkan sistem zakat dalam perekonomian (fungsi redistribusi income). Untuk trend ini sejumlah pemikiran inovatif mengenai intrmediary sistem dikembangkkan oleh para ahli ekonomi islam. Hal ini tentunya diikuti oleh kesadaran bahwa masyarakat muslim sampai saat ini masih dalam sekatan ekonomi terbelakang. Artinya permasalahan pengentasan kemiskinan dan kesenjangan sosisal (unequality income) dimiliki oleh sejumlah besar negara yang justru berpenduduk mayoritas islam.

Maka dari itu Nurul Hayat sebagai salah satu LAZNAS yang ada di indonesia memiliki peran penting dalam membantu pemerintah terkususnya di daerah madiun dan sekitarnya, untuk mengentaskan permasalah perekonomian serta sosial. Kemiskinan disinyalir kuat menjadi faktor penghambat pertumbuhan ekonomi. Sehingga tiada henti-hentinya program pengentasan kemiskinan menjadi sarana memperlakukan 'kemiskinan' sebagai obyek untuk suksesnya program-program pertumbuhan ekonomi. Kemiskinan di sini merupakan sebuah kondisi hidup yang serba kekurangan. Yusuf Qardhawi menyatakan bahwa kemiskinan sebagai salah satu penyebab munculnya permasalahan ekonomi karena lemahnya sumber penghasilan. (Qardhawi: 2005, 21) Dengan potensi zakat di Indonesia yang mencapai angka triliunan/tahun, sehingga persoalan zakat di Indonesia tetap menjadi masalah yang belum tuntas penyelesaiannya sampai kini. Membutuhkan riset serta programprogram secara sistematis sehingga hasil dari sebuah program memiliki dampak ekonomi baik mikro maupun makro. 
Di Laznas nurul hayat bukan hanya sektor ekonomi saja yang di perhatikan, tetapi di sektor dakwah, kesehatan, pendidikan, dan sosial kemanusian juga tidak kalah di perhatikan. Sebagai langganan pemenang gelar lembaga pemberdayaan terbaik semenjak tahun 2016 - 2020, laznas nurul hanyat sudah di banyak mendapatkan apresiasi baik dari masyarakat indonesia, di laznas nurul hayat banyak melibatkan organisasi msayarakat atau masyarakat sekitar untuk pelaksanaan program-programnya, seperti dalam program 10.000 pohon untuk indonesia, di program ini laznas nurul hayat melibatkan Komunitas Pemuda Untuk Pacitan, Trash Hero Pacitan, Mapala STKIP Pacitan, dan mahasiswa magang dari jurusan manajemen zakat dan wakaf iain ponorogo, dalam program ini tidak hanya bertujuan penanaman pohon pada kawasan hutan rusak yang berupa lahan kosong saja, tetapi bertujuan untuk menjalin kerjasama untuk kedapanya, semisal jika terjadi bencana alam atau masyarakat sekitar yang membutuhkan bantuan bisa langsung di informasikan ke laznas nurul hayat.

Ada juga program perbaikan/pembuatan masjid, mushola, dan pondok pesantren. Di program ini nurul hayat juga melibatkan masyarakat sekitar untuk bantuannya, baik itu berupa tenaga atau biaya pembangunan. Karean jika semua pembiayaan/dana di cukupi dari pihak Nurul Hayat, di khawaritkan masyarakat sekitar tidak merasa memiliki atau mempunyai yang mana tidak mau merawat apa yang sudah di perbaiki atau apa yang sudah di buat, maka hasil yang di harapkan dari program ini adalah masyarakat bisa menjaga dan merawat dengan baik. 
Di sektor pendidikan juga ada program "Sahabat Yatim” yang mana program terebut memberikan beasiswa untuk anak yatim yang bertujuan agar lebih termotivasi dalam menuntut ilmu dan di harapkan di masa depan bisa memperbaiki ekonomi keluarga. Rosulullah bersabda dalam hadist yang di riwayatakan oleh Bukhari, Tirmidzi, Abu Daud dan Ahmad dari Sahl bin Sa'd. Yang artinya

"Aku dan orang yang mengasuh atau memelihara anak yatim akan berada di surga begini," kemudian beliau mengisyaratkan dengan jari telunjuk dan jari tengah dan merenggangkannya sedikit."

Hadits tersebut menyatakan bahwa siapapun yang menyantuni dan memelihara anak yatim akan menjadi dekat dengan Rasulullah SAW di surga nanti. Selain itu, dijelaskan pula dalam sebuah hadits bahwa keutamaan memelihara anak yatim adalah dijamin masuk surga jika tidak melakukan dosa yang tidak dapat diampuni. (Arin Setiyowati)

\subsection{Strategi LAZNAS Nurul Hayat Cabang Madiun}

a. Program-program LAZNAS Nurul Hayat Cabang Madiun

Program adalah hal yang sangat harus dibuat oleh setiap lembaga amil zakat. Dengan adanya program, sistem pendistribusian dapat dilakukan oleh lembaga Amil Zakat Nurul Hayat. Program ini direncanakan dan dilakukan sesuai dengan visi dan misi dari lembaga Amil Zakat itu sendiri. Nurul Hayat banyak membuat program yang telah direncanakan sesuai dengan visi dan misi, berikut program dari LAZNAS Nurul Hyat Cabang Madiun yaitu: 
1) Sektor Sosial Kemanusiaan

Di dalam bidang sosial kemanusiaan program dari LAZNAS Nurul Hayat Cabang Madiun beragam mulai dari pemberian bantuan kepada korban bencana alam, IBUQU (Insentif dan Pembinaan Potensi Guru Qur'an), SAJADA (Santunan Janda Dhuafa), SURGA Desa (Sumber Air untuk Desa), Warung Berkah, Pesantren Lansia, Qurban Salur, hingga bantuan mobil jenazah yang gunanya untuk meringankan beban perekonomian. Terutama bantuan ini di berikan kepada orang-orang yang terkena musibah baik bencana alam maupun konflik antara golongan.

2) Sektor Kesehatan

Melalui bidang kesehatan ini LAZNAS Nurul Hayat Cabang Madiun memberikan bantuan pengobatan kepada orang-orang yang kurang mampu untuk berobat dengan cara membantu pengobatan, tidak hanya untuk pengobatan juga memberikan santunan dan khitan massal. Dimana harapannya setelah diberikan bantuan dapat meringankan beban biaya berobat agar cepat sembuh.

3) Sektor Pendidikan

Tidak hanya berfokus pada bidang sosial, dan kesehatan LAZNAS Nurul Hayat Cabang Madiun juga berfokus pada bidang pendidikan. Telah banyak program di LAZNAS Nurul Hayat Cabang Madiun di sektor pendidikan ini, di mualai dari beasiswa sampai dengan sahabat yatim. Dimana harapannya setelah di berikan beasiswa pendidikan ini lebih termotivasi untuk belajar lebih giat guna kedepannya 
bisa merubah ekonomi keluarga dan meringankan beban orang tua.

4) Bidang Dakwah dan Ekonomi

Selain di bidang sosial kemanusian, kesehatan, dan pendidikan di LAZNAS Nurul Hayat Cabang Madiun juga mempunya program di bidang dakwah dan ekonomi, program di bidang dakwah meliputi: Matabaca, Ibuqu, Tafaqur, Sahabat Muallaf, Dan masih banyak lagi, sangat banyak sekali program di bidang dakwah ini karena pentingnya mengajak umat islam ke jalan Allah, Allah telah menyebutkan di dalam ayatnya di QS yusuf ayat 108 yang artinya : Katakanlah: Inilah jalan (agama)ku, aku dan orangorang yang mengikutiku mengajak (kamu) kepada Allah dengan hujjah yang nyata, Maha Suci Allah, dan aku tiada termasuk orang-orang yang musyrik.

Yang tidak kalah penting dari bidang dakwah adalah di bidang ekonomi, bantuan ekonomi yang dikembangkan LAZNAS Nurul Hayat Cabang Madiun untuk membantu mustahik bukan hanya mewujudkan modal untuk berusaha, namun juga pembelajaran dan pendampingan produksi berbagai sektor ekonomi mustahik serta menguatkan pemasaran berbagai produk mustahik secara berkelanjutan. LAZNAS Nurul Hayat Cabang Madiun tidak diberikan dengan paradigma santunan tetapi melalui mekanisme yang lebih mendidik dan memberdayakan. 


\subsection{Pelaksanaan Program-program LAZNAS Nurul Hayat Cabang Madiun}

a. Sektor Sosial Kemanusiaan

LAZ Nurul Hayat Cabang Madiun membantu meringankan perekonomian para guru TPA/TPQ yang tidak mendapatkan gaji dengan program IBUQU. program IBUQU dilakukan dengan memberikan insentif bulanan kepada pengajar TPA/TPQ di wilayah Madiun dan sekitarnya yang sebelumnya telah terdaftar. Saat ini sudah ada 500 Guru pengajar TPA/TPQ. Insentif diberikan, sementara para guru menyerahkan absensi kehadirannya mengajar di TPA/TPQ masing-masing setiap satu bulan sekali. Di sektor kemanusiaan lainnya bersifat kondisional, yaitu saat terjadi bencana alam baik di wilayah lokal, nasional, maupun internasional yang dampaknya besar, maka LAZ Nurul Hayat Cabang Madiun tidak ketinggalan untuk ikut membantu baik berupa dana sosial maupun barang keperluan yang sedang dibutuhkan para korban benana. Dan masih banyak lagi programprogram di sektor kemanusiaan seperti SAJADA (Santunan Janda Dhuafa'), SURGA Desa (Sumber Air untuk Desa), Warung Berkah, Ambulance / Mobil Jenazah, zakat fitrah, dan lain sebagainya.

\begin{tabular}{|l|l|l|l|l|}
\hline & & JUNI & JULI & AGUSTUS \\
\hline $\begin{array}{l}\text { SEKTOR } \\
\text { SOSIAL } \\
\text { KEMANUSIAAN }\end{array}$ & & 1.707 .000 & $\mathbf{2 . 5 5 0 . 0 0 0}$ & $\mathbf{4 3 2 . 8 7 0 . 5 6 2}$ \\
\hline
\end{tabular}




\begin{tabular}{|c|c|c|c|c|}
\hline IBUQU & 19 & & & 500.000 \\
\hline Bencana Alam & 16 & & 50.000 & \\
\hline Maluku Gempa & 416 & & & \\
\hline Palestina & 14 & & 600.000 & \\
\hline Rohingya & 15 & & & \\
\hline Syuria / Ghouta & 33 & & & \\
\hline Dana Sosial & 17 & 1.250 .000 & & \\
\hline $\begin{array}{l}\text { SAJADA } \\
\text { (Santunan Janda } \\
\text { Dhuafa") }\end{array}$ & 18 & & 1.070 .000 & \\
\hline $\begin{array}{l}\text { SURGA Desa } \\
\text { (Sumber Air untuk } \\
\text { Desa) }\end{array}$ & 20 & 257.000 & & 620.562 \\
\hline Warung Berkah & 39 & 200.000 & 830.000 & 250.000 \\
\hline Pesantren Lansia & 48 & & & \\
\hline Qurban Salur & & & & 431.400 .000 \\
\hline $\begin{array}{l}\text { Ambulance / } \\
\text { Mobil Jenazah / } \\
\text { Mobil Resque }\end{array}$ & 21 & & & 100.000 \\
\hline Seraya & 43 & & & \\
\hline Fidyah & 40 & & & \\
\hline Zakat Fitrah & 44 & & & \\
\hline
\end{tabular}


Wabah

49

Sumber : Data Penyaluran Dana Sektor Sosial Kemanusian Pada

Bulan Juni, Juli, dan Agustus Pada Tahun 2020 LASNAS Nurul

\section{Hayat Kantor Cabang Madiun}

b. Sektor Kesehatan

Pada bulan ini khususnya, LAZNAS Nurul Hayat Cabang Madiun telah menerapkan program SAHABAT dengan memberi santunan kesehatan untuk pengobatan. Ada adik Elvano yang masih berumur kurang dari 1 tahun sedang menderita Hidrosefalus yaitu kelebihan cairan otak, sehingga membuat kepalanya besar sejak lahir. Ada juga adik Elvangga yang berumur 12 tahun yang kekurangan cairan otak sehingga membuatnya tidak bisa mandiri dan harus selalu di bawah pengawasan orang tua. Oleh karena itu LAZNAS Nurul Hayat Cabang Madiun membantu menyalurkan dana dari para donatur LAZNAS Nurul Hayat Cabang Madiun dengan memberi bantuan berupa uang dan barang kebutuhan sehari-hari yang sedang dibutuhkan sang adik.

\begin{tabular}{|l|l|l|l|l|l|}
\hline & & & JUNI & JULI & $\begin{array}{l}\text { AGUS } \\
\text { TUS }\end{array}$ \\
\hline 2 & $\begin{array}{l}\text { SEKTOR } \\
\text { KESEHATAN }\end{array}$ & & $\begin{array}{l}\mathbf{7 . 2 5 0 . 0} \\
\mathbf{0 0}\end{array}$ & $\begin{array}{l}\mathbf{1 5 . 7 0 0 .} \\
\mathbf{0 0 0}\end{array}$ & $\begin{array}{l}\mathbf{1 1 . 2 1 7 .} \\
\mathbf{9 5 5}\end{array}$ \\
\hline $\begin{array}{l}\text { SAHABAT (Santunan } \\
\text { Kesehatan }\end{array}$ & $\begin{array}{l}\text { Kenan } \\
\text { Pengobatan) }\end{array}$ & 34 & 00 & 000 & 955 \\
\hline 2. & Klinik Dhuafa \& & 26 & & 2.400 .0 & 11.217. \\
\hline
\end{tabular}




\begin{tabular}{|l|l|l|l|l|l|}
\hline 2 & Khitan Massal & & & 00 & \\
\hline
\end{tabular}

\section{Sumber : Data Penyaluran Dana Sektor Kesehatan Pada Bulan} Juni, Juli, dan Agustus Pada Tahun 2020 LASNAS Nurul Hayat Kantor Cabang Madiun

c. Sektor Pendidikan

Di LAZNAS Nurul Hayat Cabang Madiun terdapat pondok pesantren Khairunnas. Pesantren putra dan putri ini diperuntukkan bagi siswa-siswi SMP. Para santri di LAZNAS Nurul Hayat Cabang Madiun ini sebagian besar dari golongan kurang mampu, dan yatim atau piatu. Mereka dibiayai oleh para donatur LAZNAS Nurul Hayat Cabang Madiun. Ada juga Sekolah Hafizh Junior yang diperuntukkan bagi adik-adik yang ingin belajar menghafal Al-Qur'an. Hal ini membuktikan bahwa LAZNAS Nurul Hayat Cabang Madiun juga memerhatikan kualitas generasi bangsa untuk menempuh pendidikan dengan membantu anakanak yang kurang mampu dapat memperoleh haknya mengenyam pendidikan.

\begin{tabular}{|l|l|l|l|l|l|}
\cline { 3 - 5 } \multicolumn{2}{c|}{} & JUNI & JULI & $\begin{array}{l}\text { AGUSTU } \\
\text { S }\end{array}$ \\
\hline 1 & $\begin{array}{l}\text { SEKTOR } \\
\text { PENDIDIKAN }\end{array}$ & $\begin{array}{l}\mathbf{1 4 3 . 0 0 5 . 0} \\
\mathbf{0 0}\end{array}$ & $\begin{array}{l}\mathbf{1 6 6 . 0 9 6 . 5} \\
\mathbf{2 5}\end{array}$ & $\begin{array}{l}\mathbf{1 8 2 . 6 7 0 . 6} \\
\mathbf{4 2}\end{array}$ \\
\hline 1. & 2 & 126.754 .0 & 146.361 .0 & 144.520 .6 \\
1 & Sahabat Yatim & 5 & 00 & 25 & 03 \\
1. & Pembangunan & 2 & 16.251 .00 & 19.535 .50 & 37.450 .03 \\
\hline
\end{tabular}




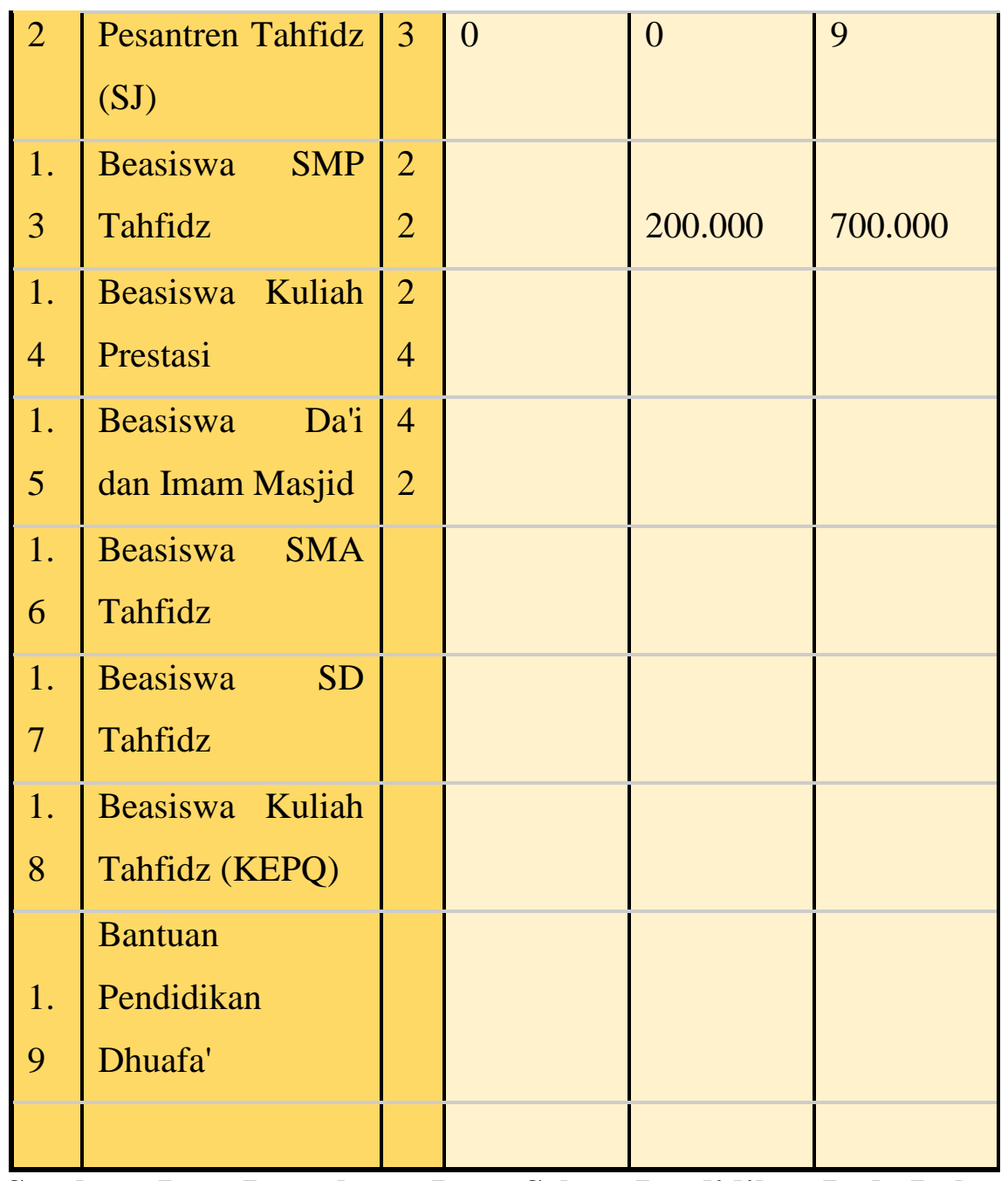

Sumber : Data Penyaluran Dana Sektor Pendidikan Pada Bulan Juni, Juli, dan Agustus Pada Tahun 2020 LASNAS Nurul Hayat Kantor Cabang Madiun

d. Bidang Dakwah dan Ekonomi

Pemberdayaan ekonomi di Nurul Hayat dilakukan dengan cara pemantauan. Pemantauan disini adalah mengunjungi langsung ke rumah mustahiknya sepekan sekali. Untuk pengembangan ekonomi mustahik di Nurul Hayat sendiri ialah 
dengan adanya salah satu program dari LAZNAS yaitu adanya warung berkah. Dengan adanya warung berkah yaitu warung yang modal usahanya di subsidi oleh LAZNAS Nurul Hayat Cabang Madiun dan memberikan makanan gratis bagi para kaum duafa setiap hari jumat. Pengembangan ekonominya ialah kepada si penjual warung berkah tersebut akan mendapatkan keuntungan dari modal yang telah Nurul Hayat berikan akan tetapi tetap setiap harinya memiliki catatan laporan keuangan yang harus dimiliki si penjual warung berkah tersebut agar termanajeman keuangannya apakah untung atau malah rugi.

\subsection{Social Entrepreneurship di LAZNAS Nurul Hayat Cabang Madiun}

Social entrepreneurship yang memiliki pengertian yaitu mengindentifikasi ataupun melihat berbagai macam masalah yang diperoleh dalam berbisnis sebagai peluang guna membentuk jenis usaha yang baru dan bermanfaat bagi adanya pemberdayaan masyarakat di sekitar lokasi usaha. Dikarenakan sifatnya adalah sosial, maka tujuan utama dari bisnis ini bukanlah untuk mencari keuntungan maksimal dan sebesar-besarnya. Selain itu tujuannya juga bukan untuk memperoleh kepuasan pelanggan namun lebih mengarah kepada hasil dari gagasan yang dibuat oleh perusahaan apakah bisa memberikan dampak positif bagi masyarakat.

Sejak awal Yayasan Nurul Hayat ini didirikan sudah berkomitmen bahwasannya gaji dan operasional yayasan tidak menggunakan dana Zakat, Infaq, dan Sedekah (ZIS) melainkan dana dari devisi usaha. Maka dari itu, dalam menjaga komitmen tersebut Nurul Hayat 
memiliki beberapa devisi usaha yang terus dikembangkan. Diantara beberapa devisi usaha yang dijalankan oleh Nurul Hayat adalah aqiqoh dan qurban siap saji, majalah anas (anak sholeh), tour and trevel umroh dan haji, herbalshop, BARBEKU (Barang Bekas Berkualitas), percetakan yang sampai sekarang akan terus dikembangkan.

\section{PENUTUP}

\subsection{Kesimpulan}

Dari penelitian yang telah dilakukan, maka peneliti menyimpulkan, bahwa LAZNAS Nurul Hayat Cabang Madiun sebagai salah satu LAZNAS yang ada di Indonesia memiliki peran penting dalam membantu pemerintah terkususnya di daerah madiun dan sekitarnya, untuk mengentaskan permasalah perekonomian serta sosial. Strategi pengelolaan zakat secara produktif di Lembaga Amil Zakat Nurul Hayat Cabang Madiun melalui beberapa kegiatan dan tahapan di berbagai sektor seperti sektor sosial kemanusiaan, sektor kesehatan, sektor pendidikan, dan sektor dakwah dan ekonomi. Berbagai program yang telah dilakukan LAZNAS Nurul Hayat Cabang Madiun tersebut merupakan bentuk peran LAZNAS Nurul Hayat dalam upaya pengentasan masalah perekonomian di Indonesia.

Program-program yang ada di LAZNAS Nurul Hayat Cabang Madiun ini direncanakan dan dilakukan sesuai dengan visi dan misi dari Lembaga Amil Zakat itu sendiri. Adapun program-program tersebut diantaranya yaitu, Insentif dan Pembinaan Potensi Guru Qur'an (IBUQU), Sumber Air Bersih, Layanan Ambulance, Santunan Bagi Penghafal Al-Qur'an (TAFAQUR), Bunda Yatim, dan 
sebagainya. Semua program dilaksanakan sesuai dengan prosedur yang berlaku di LAZNAS Nurul Hayat dan sesuai dengan Undangundang.

Yayasan Nurul Hayat berkomitmen bahwasannya gaji dan operasional yayasan tidak menggunakan dana Zakat, Infaq, dan Sedekah (ZIS) melainkan dana dari devisi usaha. Dalam menjaga komitmen tersebut Nurul Hayat memiliki beberapa devisi usaha yang terus dikembangkan seperti aqiqoh dan qurban siap saji, majalah anas (anak sholeh), tour and trevel umroh dan haji, herbalshop, BARBEKU (Barang Bekas Berkualitas), dan percetakan.

\subsection{Saran}

Saran dalam upaya mengoptimalisasi peran LAZNAS Nurul Hayat Cabang Madiun dalam upaya mengentaskan perekonomian masyarakat melalui zakat, infak, dan sedekah, yaitu mempertahankan atau meningkatkan pengoptimalan pengelolaan dan memaksimalkan pengumpulan, pendistribusian dan pendayagunaan zakat, infak dan sedekah. Karena jika hal ini terus ditingkatkan maka hal ini dapat menjadikan dana ZIS benar-benar berperan dalam peningkatan kesejahteraan masyarakat.

Selain itu, LAZNAS Nurul Hayat Cabang Madiun harus lebih meningkatkan dan menjalankan program yang berkaitan dengan pemberdayaan dan pendampingan masyarakat. Karena kegiatan pemberdayan merupakan kegiatan yang produktif dan dapat dilakukan dalam jangka waku lama. 
Untuk peneliti selanjutnya, hasil penelitian ini bisa digunakan sebagai bahan perbandingan dan referensi penelitian, serta sebagai bahan pertimbangan untuk lebih memperdalam penelitian selanjutnya.

\section{REFERENSI}

\section{Books}

Abidah, Atik. (2011). Zakat Filantropi dalam Islam. Ponorogo: STAIN Ponorogo Press.,.

Adi, Rianto. (2004). Metodelogi Penelitian Sosial dan Hukum. Jakarta: Granit.

Amiruddin, \& Asikin, Zainal. (2007). Pengantar Metode Penelitian Hukum. Jakarta: Rajawali Pers.

BAZNAS. (2018). Outook Zakat Indonesia. Jakarta: Puskas Baznas.

Hasan, M. Ali. (2006). Zakat dan Infak Salah Satu Solusi Mengatasi Problem Sosial di Indonesia. Jakarta: Prenadamedia Grup.

Majalah Nurul Hayat Madiun. (November 2020). Jangan Bodoh. Edisi 202.

Mardiantari, Ani. (2019). "Peranan Zakat, Infak dan Sedekah (ZIS) dalam Upaya Meningkatkan Perekonomian Masyarakat Kota Metro”. Jurnal Syariah dan Hukum. 17.

Muhammad. (2009). Lembaga Keuangan Mikro Syariah. Yogyakarta: Graha Ilmu. Cet. 1.

Qardhawi, Yusuf. (2005). "Daur al-Zakat fi Ilaj al-Musykilat alIqtishadiyyah". Diterjemahkan oleh Narulita, Sari. Spektrum Zakat Membangun Ekonomi Kerakyatan. Jakarta: Zikrul Hakim. 
Departemen Agama Republik Indonesia Jakarta. (2004). Al-Qur'an dan Terjemahnya. QS al-Anbiya, ayat 107. Cv. Al Waah: Semarang.

Sahhatih, Syauqi Ismail. (2007). "Penerapan zakat dalam bisnis modern". Diterjemahkan dari buku: At-Tathbiq Al-Amu'ashir Lizzakah. Bandung: CV Pustaka Setia.

Soejono, \& Mamudji, Sri. (2006). Penelitian Hukum Normatif. Jakarta: Raja Grafindo Persada.

Sunggono, Bambang. (1997). Metodologi Penelitian Hukum. Jakarta: Raja Grafindo Persada.

\section{Jurnal}

Setiyowat, Arin. "Analisis Peranan Pengelolaan Dana Ziswaf oleh Civil Society dalam Pemberdayaan Ekonomi Umat”. Jurnal Masharif al-Syariah: Jurnal Ekonomi dan Perbankan Syariah. Universitas Muhammadiyah, Surabaya.

\section{Hasil wawancara}

Hasil wawancara dengan direktur LAZNAS Nurul Hayat Kantor Cabang Madiun. (26 Oktober 2020). 